\title{
The 14th international workshop on wave hindcasting and forecasting and the 5th coastal hazards symposium
}

\author{
Øyvind Breivik ${ }^{1,2}$ (D) . Jose Henrique Alves ${ }^{3}$. Diana Greenslade ${ }^{4}$. \\ Kevin Horsburgh ${ }^{5} \cdot$ Val Swail $^{6}$
}

Received: 16 January 2017 / Accepted: 17 January 2017 / Published online: 6 February 2017

(C) Springer-Verlag Berlin Heidelberg 2017

\begin{abstract}
Following the 14th International Workshop on Wave Hindcasting and Forecasting and 5th Coastal Hazards Symposium in November 2014 in Key West, Florida, a topical collection has appeared in recent issues of Ocean Dynamics. Here, we give a brief overview of the 16 papers published in this topical collection as well as an overview of the widening scope of the conference in recent years. A general trend in the field has been towards closer integration between the wave and ocean modelling communities. This is also seen in this topical collection, with several papers exploring the interaction between surface waves and mixed layer dynamics and sea ice.
\end{abstract}

Responsible Editor: Jörg-Olaf Wolff

Øyvind Breivik

oyvind.breivik@met.no

1 Norwegian Meteorological Institute, Alleg 70, 5007 Bergen, Norway

2 The Geophysical Institute, University of Bergen, Alleg 70, 5007 Bergen, Norway

3 Environmental Modeling Center, National Centers for Environmental Prediction, National Oceanic and Atmospheric Administration, Silver Spring, MD, USA

4 Bureau of Meteorology, Melbourne, Australia

5 National Oceanography Centre, Liverpool, UK

6 Climate Research Division, Environment and Climate Change Canada, Toronto, ON, Canada
Keywords Wave modelling - Wave hindcasting · Wave measurements · Wave theory · Coastal hazards · Storm surges $\cdot$ Water level forecasting

\section{History of the workshop}

The history of the International Workshop on Wave Hindcas ting and Forecasting was presented by Breivik et al. (2015b) where the topical collection following the 13th International Workshop on Wave Hindcasting and Forecasting and 4th Coastal Hazards Symposium was presented. At the following workshop, held in Key West, Florida, in November 2015, it was decided that the next workshop would for the first time be held outside North America. It will be hosted by the National Oceanography Centre as the first International Workshop on Waves, Storm Surges and Coastal Hazards in Liverpool, UK, 10-15 September 2017. This will further broaden the scope of the workshops to foster closer integration between the wave and ocean modelling communities, such as the emerging priority of multi-hazard early warning systems (MHEWS) for coastal inundation resulting from the combined effects of waves, storm surges, tides, etc., e.g. the WMO Coastal Inundation Forecasting Demonstration Project (CIFDP). It will also shorten the title of the workshop series, which grew in 2007 when the International Workshop on Wave Hindcasting and Forecasting was joined by the Coastal Hazards Symposium. The title grew further in 2015 when it was joined by the 2nd JCOMM Scientific and Technical Symposium on Storm Surges. Despite the new integrated workshop title, the Wave Workshop will continue to be explicitly identified as a component of the meeting (with the 15th Wave Workshop in 2017), to maintain the successful legacy of the previous workshops, including the workshop web site www.waveworkshop.org. 
It is now more than 30 years since the first International Workshop on Wave Hindcasting and Forecasting was held in Halifax, Nova Scotia, Canada in September 1986. As described by Breivik et al. (2015b), the research tools and the topics have changed over the years, but we can still recognise the primary objectives of the first workshop, namely to

- Provide a forum for the exchange of ideas and information related to wind and wave hindcasting and forecasting, including modelling, measurement and past and future states of the climate

- Coordinate ongoing research and development initiatives

- Discuss priorities for future research and development

\section{The 14th workshop}

The 14th International Workshop on Wave Hindcasting and Forecasting and the 5th Coastal Hazards Symposium (henceforth referred to as the Workshop) was held in Key West, Florida, USA, from 8 to 13 November, 2015. The workshop counted 147 participants who gave over 118 presentations and displayed 11 posters. For the first time, the conference was split into parallel sessions. This strategy received a mixed response, as many participants felt that the strength of the workshop series has been that all the attendees are gathered in one plenary session where discussions at times can run high, offering an opportunity to also follow what is going on in neighbouring scientific disciplines. It was announced that the next workshop will endeavour to return to a plenary format. The session topics were

- Wave Measurement-In Situ

- Wave Measurement-Remote Sensing

- Wave Climate

- Wave Climate and Design

- Wave Forecasting Developments

- Wave Forecasting

- Wave Hindcasts and Climate Change

- Wave Modelling

- Tropical Systems

- Storm Surge Forecasting and Climate

- Storm Surge Modelling

- Storm Surge Forecasting

- Mississippi Delta and the Jersey Shore

- The WMO Coastal Inundation Forecasting Demonstration Project

- The North Atlantic Coast Comprehensive Study

- Coastal Processes

- Operational Forecast Challenges and Issues

- Coastal Impacts

- Living Shorelines
In addition to the general sessions, the workshop had theme sessions, as is always the case for this workshop series. The special topics were (i) "Developing improved methods for wave prediction in complex conditions and environments" and (ii) "Operational advances in wave prediction capabilities". The Coastal Hazards Symposium had "Developing Tools for Quantifying Future Coastal and Offshore Risks and Resiliency" as its special topic.

Sixteen papers relating to the Workshop have been published in this topical collection. A brief summary of these papers follows.

Several authors considered wave-ice interactions. Collins et al. (2017) investigated four different dispersion models of ocean surface gravity waves in ice. For each dispersion model, model parameters were varied to study the dependence of dispersion on ice thickness, elasticity, and viscosity. In all cases, the deviation of wavenumber from the open water relation is more pronounced for higher frequencies. The effect of mass-loading, a component of all dispersion models, tends to shorten the wavelength whereas elasticity in the elastic plate model and viscosity in the viscous-layer model tend to increase the wavelength. The net effect, lengthening or shortening, is a function of the particular combination of ice parameters and wave frequency. Empirical results were compiled and interpreted in the context of these theoretical models of dispersion.

Gebhardt et al. (2016) investigated the penetration of ocean waves into the marginal ice zone (MIZ) with synthetic aperture radar images from the TerraSAR-X satellite and numerical simulations of the European Centre for MediumRange Weather Forecasts (ECMWF). The study focussed on a swell event from a passing storm in the North Atlantic which penetrated deeply into the MIZ off the coast of Eastern Greenland in February 2013. The authors found an increase in wavelength which is consistent with the spatial dispersion of deep water waves, even within the ice-covered region.

Several papers made use of non-traditional observational methods. Gemmrich et al. (2016) assessed the spatial variability of open ocean wave fields on scales of $\mathcal{O}(10 \mathrm{~km})$ from four different data sources: (i) TerraSAR-X SAR imagery, (ii) four drifting SWIFT buoys, (iii) a moored waverider buoy and (iv) WAVEWATCH-III (WW3, Tolman 1991; Tolman et al. 2002, 2009) model runs. Two examples from the open northeast Pacific, comprising a pure wind sea and a mixed sea with swell, were given. Wave parameters attained from observations have a natural variability, which decreases with increasing record length or acquisition area. The retrieval of dominant wave scales from point observations and model output are inherently different to dominant scales retrieved from spatial observations. This can lead to significant differences in the dominant steepness associated with a given wave field. These uncertainties have to be taken 
into account when models are assessed against observations or when new wave retrieval algorithms from spatial or temporal data are tested. However, there is evidence of abrupt changes in wave field characteristics that are larger than the expected methodological uncertainties.

Lund et al. (2016) investigated the performance of marine $\mathrm{X}$-band radars (MRs) in the Philippine Sea. Spreading parameters derived from two-dimensional radar spectra were compared to buoy spreading functions and the radar spectra were also compared directly to WW3 modelled spectra. A new MR wave retrieval technique was introduced that addresses various shortcomings of existing methods. Both buoy and model data sets are in good agreement with MR data, tracking the evolution of up to four simultaneous wave systems over extended time periods.

Hole et al. (2016) presented a new autonomous vessel, the Offshore Sensing Sailbuoy, which has been employed for wave measurements near the Ekofisk oil platform complex in the North Sea $\left(56.5^{\circ} \mathrm{N}, 3.2^{\circ}\right.$ E) during a field campaign in November 2015. The Sailbuoy is propelled by wind alone and has two-way communication via the Iridium network. It can operate for periods of more than 6 months and has previously been deployed in the Arctic, the Norwegian Sea and the Gulf of Mexico. The present study was however the first test for wave measurements. During the campaign the Sailbuoy held position about $20 \mathrm{~km}$ northeast of Ekofisk (on the lee side) during rough conditions. The Sailbuoy measurements were compared with non-directional Waverider observations at the Ekofisk complex. The agreement between the two data sets was good, with a mean absolute error of $7 \%$ and a linear correlation coefficient of 0.97 . The wave frequency spectra measured by the two instruments compared very well, except for low $H_{\mathrm{s}}$ (ca $\left.1 \mathrm{~m}\right)$, where the motion of the vessel seemed to influence the measurements. Nevertheless, the Sailbuoy performed well during this campaign, suggesting that it is a suitable platform for wave measurements in a broad range of sea states.

Several authors focussed on wave model development, and model evaluation. van Vledder et al. (2016) presented a wave hindcast of a severe storm in the Southern North Sea with the objective of assessing recently developed deep and shallow water source terms for use in third-generation wave prediction models. These deep water source terms for whitecapping, wind input and nonlinear interactions were developed, implemented and tested primarily in WW3, whereas shallow water source terms for depth-limited wave breaking and triad interactions were developed, implemented and tested primarily in the SWAN wave model Ris et al. (1999) and Booij et al. (1999). Their performance and the impact of different physical settings on the prediction of wave heights and wave periods in the relatively shallow North Sea was analysed for the December 2013 storm (which was also investigated by Staneva et al. 2017). Spectral wave boundary conditions were obtained from an Atlantic Ocean WAVEWATCH III model implementation and the model was driven by hourly wind fields from the Climate Forecast System Reanalysis (CFSR) (Saha et al. 2010, 2014). In the southern part of the North Sea, current and water level effects were included. The hindcast was performed with five different settings for whitecapping, viz. three Komen-type whitecapping formulations, the saturation-based whitecapping by van der Westhuysen et al. (2007) and the recently developed ST6 whitecapping described by Zieger et al. (2015). An analysis was made of the source term balance at three locations, the deep water location North Cormorant, the intermediate depth location K13 and at location Wielingen, a shallow-water location close to the Dutch coast. The results suggest that at deep water, the source terms for wind input, whitecapping and nonlinear four-wave interactions are of the same magnitude. At the intermediate depth location $\mathrm{K} 13$, bottom friction plays a significant role, whereas at the shallow water location Wielingen depth-limited wave breaking is also of importance.

Barbariol et al. (2017) presented an implementation of space-time wave extremes in WAVEWATCH III (WW3). The new output parameters, available in WW3 version 5.16, rely on the theoretical model of Fedele (2012), extended by Benetazzo et al. (2015) to estimate the maximum secondorder nonlinear crest height over a given space-time region. In order to assess the wave height associated with the maximum crest height and the maximum wave height (generally different in a broad-banded stormy sea state), the linear Quasi-Determinism theory of Boccotti (2000) is considered. The new WW3 implementation is tested by simulating sea states and space-time extremes over the Mediterranean Sea (forced by the wind fields produced by the COSMO-ME atmospheric model). Model simulations are compared to wave maxima from sea-state observations in the northern Adriatic Sea (Italy), by a stereo-camera system installed onboard the "Acqua Alta" oceanographic tower. Results show that modelled space-time extremes are in general agreement with observations. Differences are mostly ascribed to the accuracy of the wind forcing and, to a lesser extent, to the approximations introduced in the space-time extreme parameterizations. Model estimates are expected to be more accurate over areas that are larger than the mean wavelength (for instance, the model grid size).

Li (2016) presented a WAVEWATCH III model domain for the Arctic that employs the spherical multiple-cell (SMC) grid (Li and Saulter 2014). This avoids the singularity at the pole by gradually reducing the number of grid cells, thus keeping the Courant-Friedrichs-Lewy (CFL) criterion at an acceptable level. This has practical implications as the retreat of the Arctic ice edge implies that global ocean surface wave models will have to be extended to high latitudes or maybe even to cover the North Pole in the future. 
The SMC grid was implemented in the WAVEWATCH III model and compared against altimeter and buoy observations. An idealised ice-free Arctic case was presented to test the Arctic domain and was compared with a reference case with real ice coverage. The comparison indicates that swell wave energy will increase near the ice-free Arctic coastlines due to increased fetch.

Ponce de León et al. (2016) studied the ability of a thirdgeneration spectral wave model to reproduce winter sea states in the North Sea. Severe sea states in the North Sea present a challenge to wave forecasting systems and a threat to offshore installations such as oil and gas platforms and offshore wind farms. Measured and modelled time series of integral wave parameters and directional wave spectra were compared for a 12-day period in the winter (December to February) of 2013/2014 when several severe storms moved across the North Atlantic and the North Sea in succession. Records were obtained from a Doppler radar and wave buoys. The hindcast was performed with the WAVEWATCH III model with high spectral resolution both in frequency and direction. A good general agreement was obtained for integrated parameters, but discrepancies were found to occur in spectral shapes.

Moving towards papers arising from the Coastal Hazards symposium, several authors investigated water levels and currents, in addition to waves and the interactions between them. Li et al. (2016) used the Fully Adaptive Storm Tide (FAST) model to study the response of Lake Okeechobee (Florida) as hurricanes Frances, Jeanne, and Wilma passed over in September 2004 and October 2005, respectively. Strong winds caused a large surface seiche on the lake during all three storms. These storms resulted in erosion damage to dikes in the lake. Comparisons of the modelled surface water level with the observations were overall in good agreement for all three hurricanes. The results suggest that the strong currents induced by the winds may be the dominant factor controlling the dike erosion observed at the lake side as the locations of erosion damage are consistent with the modelled high-velocity zones during the storms.

Staneva et al. (2017) looked at the effect of wind waves on water level and currents during two storms in the North Sea using a high-resolution Nucleus for European Modelling of the Ocean (NEMO, see Madec and the NEMO team 2008) model forced with fluxes and fields from a high-resolution wave model, building on previous work on a global version of NEMO (Breivik et al. 2015a). The additional terms accounting for wave-current interaction that are considered in this study are the Stokes-Coriolis force (Breivik et al. 2014, 2016) the sea-state-dependent energy and wave-modulated momentum fluxes. The same regional model setup with forcing from a WAM wave model has previously been described by Alari et al. (2016) where the focus was the influence of wave effects on surface water temperature. The individual and collective role of these processes is quantified and the results are compared with a control run without wave effects as well as against current and water-level measurements from coastal stations. Two North Sea storms in November and December 2013 were used as test cases, and it was found that including the wave forcing raises the water level by $20-40 \mathrm{~cm}$ in the German Bight area, bringing the results closer to observed water levels. Moreover, the vertical velocity profile also fits the observations better when the wave forcing is included.

Kodaira et al. (2016) also employed NEMO, but here the model was set up on a global grid. The objective is to develop an operational forecast system for total water level, and to this end, a study is performed of global storm surges for the northern hemisphere autumn of 2014. The model has 19 vertical levels, a horizontal resolution of $1 / 12^{\circ}$, and is forced by hourly forecasts of atmospheric wind and air pressure. It is found that the model provides reasonable predictions of surges at 257 tide gauges with relatively large tidal residuals. It is also found that the inclusion of density stratification increases the predictive skill at almost all the tide gauges.

Zou and Xie (2016) presented a fully coupled spectral wave and circulation model consisting of the wave model SWAN and the circulation model ADCIRC. The model suite was applied to investigate tide-surge and wave interaction in the Gulf of Maine during the extratropical storm on Patriot's Day of 2007. Significant tide-surge and wave interaction was found over Georges Bank and in the coastal areas. Over Georges Bank, the wave-induced current reached $0.2 \mathrm{~m} / \mathrm{s}$ at the storm peak, accounting for $17 \%$ of the total depthaveraged current. In Saco Bay, the current was dominated by wave-induced current with a magnitude up to $1.0 \mathrm{~m} / \mathrm{s}$ during the storm. Two clockwise circulation gyres were found to form and sustain over a period of $26 \mathrm{~h}$ during the storm in the bay. They were driven by spatial variations of wave height, direction and the resulting wave radiation stress gradient. Wave setup reached $0.2 \mathrm{~m}$ at the storm peak along the coast of Saco Bay. In the bay, wave energy dissipation was reduced and wave height increased due to the increased water depth at high tide and surge. Consequently, wave height was modulated by tide and surge along the coast. As a result, wave setup and wave-induced current in the bay were also modulated by tide and surge. During the tidal cycle at the storm peak, wave setup increased with tidal level and the maximum wave setup coincided with high tide.

End user applications are also important and two papers looked at the use of wave models in offshore engineering. Bruserud and Haver (2016) compared metocean design criteria for waves and currents based on measured and hindcast data. At the Norwegian Continental Shelf (NCS), the Norwegian Hindcast Archive (NORA10, see Reistad et al. 2011; Aarnes et al. 2012; Breivik et al. 2013; Semedo et al. 
2015) for wind and waves and the Northern North Sea Current Hindcast Study (NoNoCur) for currents was employed. NORA10 waves and NoNoCur currents were compared to wave and current measurements taken during the period May 2011 to October 2015 at four locations in the northern North Sea. Significant wave height, $H_{\mathrm{s}}$, spectral peak period, $T_{\mathrm{p}}$, wave direction, as well as current speed, $U$ and direction at two water depths were compared with observations. In addition, the extreme values of $H_{\mathrm{s}}$ were estimated, the conditional log-normal distribution for $T_{\mathrm{p}}$ given $H_{\mathrm{s}}$ was considered, and the $H_{\mathrm{s}}-T_{\mathrm{p}}$ contour lines were established. Good agreement between NORA10 and measured wave data in the northern North Sea was demonstrated, although the NORA10 $H_{\mathrm{s}}$ was found to be slightly more conservative than observations. The NoNoCur data corresponded well to current measurements in the northern North Sea. However, the NoNoCur data does not correspond as good as the NORA10 data corresponds to measured data. Consequently, NORA10 can be recommended to be used for wave design criteria at NCS, while NoNoCur must be further developed and used with caution.

Zou and Kaminski (2016) looked at the applicability of WW-III to fatigue assessment of offshore floating structures. The Bluewaters Floating Production, Storage and Offloading (FPSO) installation which has been turretmoored at the Sable field about $150 \mathrm{~km}$ southwest of South Africa for half a decade was used as a specific case study. The modelled waves were compared with ERA-Interim reanalysis data (Dee et al. 2011) and buoy measurements. Fatigue calculations were carried out for main deck and side shell locations. It was found that predicted fatigue damages using WW-III were in good agreement, but the model was found to underestimate fatigue damage of the side shells by approximately $30 \%$ compared with buoy measurements. The reason was the wider directional spreading of actual waves. WW-III was generally found suitable for the fatigue assessment, but the authors concluded that more attention should be paid to wave directionality, wave system partitioning and uncertainty analysis when investigating the usefulness of wave model simulations for fatigue calculations on offshore structures.

Finally, Pampell-Manis et al. (2016) reported that Gulf of Mexico (GOM) coasts have been included in the US Tsunami Warning System since 2005. While the tsunami risk for the GOM is low, tsunamis generated by local submarine landslides pose the greatest potential threat, as evidenced by several large ancient submarine mass failures identified in the northern GOM basin. Given the lack of significant historical tsunami evidence in the GOM, the potential threat of landslide tsunamis in this region is assessed from a worstcase scenario perspective based on a set of events including the large ancient failures and most likely extreme events determined by a probabilistic approach. Since tsunamis are not well understood along the Gulf Coast, they investigated tsunami inundation referenced to category-specific hurricane storm surge levels, which are relatively well established along the Gulf Coast. This provides information for assessing the potential threat of tsunamis which is more understandable and accessible to emergency managers. The general trends indicate that tsunami inundation can well exceed the level of storm surges from major hurricanes in open beachfront and barrier island regions, while interior areas are less threatened. Such information can be used to better prepare for tsunami events as well as provide a preliminary estimate of tsunami hazard in locations where detailed tsunami inundation studies have not been completed.

The 16 articles in the topical collection show the breadth of the workshop. However, a number of excellent proceeding papers can also be found online at www.waveworkshop. org, where the long history of the workshop has been carefully archived. As the workshop now for the first time takes the leap across the Atlantic, we look forward to an even more international gathering in the coming years.

Acknowledgments The conference co-chairs would like to express their gratitude to the organizers and sponsors: JCOMM, Environment Canada and the US Army Corps of Engineers. More information about the conference can be found at http://www.waveworkshop.org.

We are grateful to Springer (publisher of Ocean Dynamics) for taking the subject into consideration for a topical collection. ØB has benefited from the RETROSPECT (grant no. 244262) and CIRFA projects (grant no. 237906), funded by the Research Council of Norway, and the WAVE2NEMO project funded by the EU Copernicus services (CMEMS), while editing this topical collection.

\section{References}

Aarnes OJ, Breivik $\varnothing$, Reistad M (2012) Wave extremes in the northeast atlantic. J Clim 25:1529-1543. doi:10/bvbr7k

Alari V, Staneva J, Breivik $\varnothing$, Bidlot J-R, Mogensen K, Janssen P (2016) Surface wave effects on water temperature in the Baltic Sea: simulations with the coupled NEMO-WAM model. Ocean Dyn 66:917-930. doi:10.1007/s10236-016-0963-x

Barbariol F et al (2017) Numerical modeling of space-time wave extremes using WAVEWATCH III. Ocean Dyn 67:15. doi:10.1007/s10236-016-1025-0. 14th wave special issue

Benetazzo A, Barbariol F, Bergamasco F, Torsello A, Carniel S, Sclavo M (2015) Observation of extreme sea waves in a space-time ensemble. J Phys Oceanogr 45(9):2261-2275. doi:10.1175/JPOD-15-0017.1

Boccotti P (2000) Wave mechanics for ocean engineering, vol 64. Elsevier

Booij N, Ris RC, Holthuijsen LH (1999) A third-generation wave model for coastal regions 1 . Model description and validation. J Geophys Res 104(C4):7649-7666. doi:10.1029/98JC02622

Breivik Ø, Aarnes OJ, Bidlot J-R, Carrasco A, Saetra Ø (2013) Wave extremes in the northeast atlantic from ensemble forecasts. J Clim 26:7525-7540. doi:10/mpf. arXiv:1304.1354

Breivik $\varnothing$, Bidlot J-R, Janssen PA (2016) A Stokes drift approximation based on the Phillips spectrum. Ocean Model 100:49-56. doi:10.1016/j.ocemod.2016.01.005. arXiv:1601.08092 
Breivik Ø, Janssen P, Bidlot J (2014) Approximate stokes drift profiles in deep water. J Phys Oceanogr 44(9):2433-2445. doi:10.1175/ JPO-D-14-0020.1. arXiv:1406.5039

Breivik $\varnothing$, Mogensen K, Bidlot J-R, Balmaseda MA, Janssen PA (2015a) Surface wave effects in the NEMO ocean model: forced and coupled experiments. J Geophys Res Oceans 120:2973-2992. doi:10.1002/2014JC010565. arXiv: 1503.07677

Breivik Ø, Swail V, Babanin A, Horsburgh K (2015b) The international workshop on wave hindcasting and forecasting and the coastal hazards symposium. Ocean Dyn 65(5):761-771. doi:10.1007/ s10236-015-0827-9, arXiv:1503.00847. 13th wave special issue

Bruserud K, Haver S (2016) Comparison of wave and current measurements to NORA10 and NoNoCur hindcast data in the northern North Sea. Ocean Dyn 66(6):823-838. doi:10.1007/s10236016-0953-z. 14th wave special issue

Collins I, Clarence O, Rogers WE, Lund B (2017) An investigation into the dispersion of ocean surface waves in sea ice. Ocean Dyn: 1-18. doi:10.1007/s10236-016-1021-4. 14th wave special issue

Dee D et al (2011) The ERA-interim reanalysis: configuration and performance of the data assimilation system. Q J R Meteorol Soc 137(656):553-597. doi:10.1002/qj.828

Fedele F (2012) Space-time extremes in short-crested storm seas. J Phys Oceanogr 42(9):1601-1615. doi:10.1175/JPO-D-11-0179.1

Gebhardt C, Bidlot J-R, Gemmrich J, Lehner S, Pleskachevsky A, Rosenthal W (2016) Wave observation in the marginal ice zone with the TerraSAR-X satellite. Ocean Dyn 66(6):839-852. doi:10.1007/s10236-016-0957-8. 14th wave special issue

Gemmrich J, Thomson J, Rogers WE, Pleskachevsky A, Lehner S (2016) Spatial characteristics of ocean surface waves. Ocean Dyn 66(8):1025-1035. doi:10.1007/s10236-016-0967-6. 14th wave special issue

Hole LR, Fer I, Peddie D (2016) Directional wave measurements using an autonomous vessel. Ocean Dyn 66(9):1087-1098. doi:10.1007/s10236-016-0969-4. 14th wave special issue

Kodaira T, Thompson KR, Bernier NB (2016) The effect of density stratification on the prediction of global storm surges. Ocean Dyn 66(12):1733-1743. doi:10.1007/s10236-016-1003-6. 14th wave special issue

Li J-G (2016) Ocean surface waves in an ice-free Arctic Ocean. Ocean Dyn 66(8):989-1004. doi:10.1007/s10236-016-0964-9. 14th wave special issue

Li J-G, Saulter A (2014) Unified global and regional wave model on a multi-resolution grid. Ocean Dyn 64(11):1657-1670. doi:10.1007/s10236-014-0774-x. 13th wave special issue

Li Y, Teng Y-C, Kelly DM, Zhang K (2016) A numerical study of the impact of hurricane-induced storm surge on the Herbert Hoover Dike at Lake Okeechobee, Florida. Ocean Dyn 66(12):1699-1714. doi:10.1007/s10236-016-1001-8. 14th wave special issue

Lund B, Collins CO, Tamura H, Graber HC (2016) Multi-directional wave spectra from marine x-band radar. Ocean Dyn 66(8):973988. doi:10.1007/s10236-016-0961-z. 14th wave special issue

Madec G, the NEMO team (2008) Nemo ocean engine. Note du Pole de modélisation 27, Institut Pierre Simon Laplace

Pampell-Manis A, Horrillo J, Figlus J (2016) Estimating tsunami inundation from hurricane storm surge predictions along the U.S. gulf coast. Ocean Dyn 66(8):1005-1024. doi:10.1007/s10236-0160966-7. 14th wave special issue

Ponce de León S, Bettencourt JH, Dias F (2016) Comparison of numerical hindcasted severe waves with Doppler radar measurements in the North Sea. Ocean Dyn 67(1):103-115. doi:10.1007/s10236-016-1014-3. 14th wave special issue

Reistad M, Breivik Ø, Haakenstad H, Aarnes OJ, Furevik BR, Bidlot J-R (2011) A high-resolution hindcast of wind and waves for the North Sea, the Norwegian Sea, and the Barents Sea. J Geophys Res 116:18. doi:10/fmnr2m. C05019, arXiv:1111.0770

Ris RC, Holthuijsen LH, Booij N (1999) A third-generation wave model for coastal regions 2. Verification. J Geophys Res 104(C4):7667-7681. doi:10.1029/1998JC900123

Saha S et al (2010) The NCEP climate forecast system reanalysis. Bull Am Meteor Soc 91(8):1015-1057. doi:10.1175/2010Bams3001.1

Saha $\mathrm{S}$ et al (2014) The NCEP climate forecast system version 2. J Clim 27:2185-2208. doi:10.1175/JCLI-D-12-00823.1

Semedo A, Vettor R, Breivik $\varnothing$, Sterl A, Reistad M, Soares CG, Lima DCA (2015) The wind sea and swell waves climate in the nordic seas. Ocean Dyn 65(2):223-240. doi:10.1007/s10236014-0788-4. 13th wave special issue

Staneva J, Alari V, Breivik Ø, Bidlot J-R, Mogensen K (2017) Effects of wave-induced forcing on a circulation model of the North Sea. Ocean Dyn 67:81-101. doi:10.1007/s10236-016-1009-0. 14th wave special issue

Tolman HL (1991) A third-generation model for wind waves on slowly varying, unsteady, and inhomogeneous depths and currents. J Phys Oceanogr 21(6):782-797. doi:10/ddxwxn

Tolman HL, Balasubramaniyan B, Burroughs LD, Chalikov DV, Chao YY, Chen HS, Gerald VM (2002) Development and implementation of wind-generated ocean surface wave models at NCEP. Wea Forecast 17(2):311-333. doi:10/d74ttq

Tolman HL et al (2009) User manual and system documentation of WAVEWATCH III TM version 3.14. Tech. Rep. 276, MMAB/ NCEP/NOAA

van der Westhuysen A, MZ, Battjes J (2007) Nonlinear saturationbased whitecapping dissipation in SWAN for deep and shallow water. Coast Eng 54(2):151-170. doi:10.1016/j.coastaleng.2006. 08.006

van Vledder GP, Hulst STC, McConochie JD (2016) Source term balance in a severe storm in the Southern North Sea. Ocean Dyn 66(12):1681-1697. doi:10.1007/s10236-016-0998-z. 14th wave special issue

Zieger S, Babanin AV, Rogers WE, Young IR (2015) Observationbased source terms in the third-generation wave model WAVEWATCH. Ocean Model 96, Part 1:2-25. doi:10.1016/j.ocemod. 2015.07.014

Zou Q, Xie D (2016) Tide-surge and wave interaction in the Gulf of Maine during an extratropical storm. Ocean Dyn 66(12):17151732. doi:10.1007/s10236-016-1002-7. 14th wave special issue

Zou T, Kaminski ML (2016) Applicability of wavewatch-iii wave model to fatigue assessment of offshore floating structures. Ocean Dyn 66(9):1099-1108. doi:10.1007/s10236-016-0977-4. 14 th wave special issue 